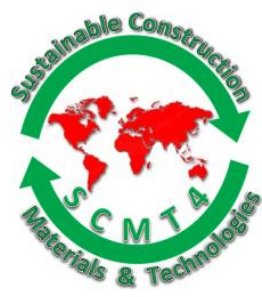

SCMT4

Las Vegas, USA, August 7-11, 2016

\title{
Improvement of Flexural Performance of Fibre Cements Composite Board through Fibre Impregnation
}

\author{
Morteza Khorami $^{1 \mathrm{a}}$, and Eshmaiel Ganjian ${ }^{1 \mathrm{~b}}$ \\ ${ }^{1}$ Coventry University, Coventry, UK, \\ ${ }^{I a}$ Email :<M.khorami@coventry.ac.uk >; ${ }^{1 b}$ Email :<E.Ganjian@coventry.ac.uk >.
}

\begin{abstract}
Fibre-cement composite board (FCCB) is one of the most important construction products that can be employed in construction systems as an internal/external wall and also as a material for roofing or cladding. Largely, the main fibre used in FCCB is natural fibres; particularly cellulose fibres extracted from Kraft pulp. Exposing cellulose fibre in alkaline media as a result of cement hydration causes a deterioration on fibres.

This laboratory research investigated pre-treatment methods for preventing or reducing cellulose fibres deterioration in alkaline media. Three types of solutions were examined; Potassium Sulphate, Magnesium Sulphate and Sodium Silicate, these were applied in the treatment of Kraft fibres. Next, three groups of specimens were made using laboratory simulated Hatcheck process, having six specimens in each group. Then, flexural performance; one of the most important mechanical properties of FCCB; was investigated in the aforementioned groups of FCCB aged 7 and 28 days. The results showed that Magnesium Sulphate has the best effect on improving the bond within fibre-cement interfacial zone and could increase the flexural strength of FCCB's.
\end{abstract}

\section{INTRODUCTION}

The beneficial uses of cellulose fibres have drawn the attention of researchers in incorporating cellulose fibres in the production of cement board. Benefits include; sustainability, availability, renewability, welldeveloped technology to extract the fibres, elastic modulus, and the relatively low cost.

Cellulose fibres are one of the most important natural fibres that have been used in the production of fibre cement board. Cellulose fibres may be extracted from different sources; such as waste paper/cardboard, wood pulp and even agricultural by products (Coutts 2005, Ganjian and Khorami 2008).

However, one of the main drawbacks of cellulose fibres is that they often deteriorate in alkaline media due to the presence of lignin in the fibres. The alkaline media dissolves the lignin and hemicellulose phases, hence causing the fibres to become weak (Jarabo et al. 2012, Khorami and Ganjian 2011, S.R. 2010). 
Production of cellulose fibres could be conducted using various method of processing including mechanical and chemical processing. The most common method is chemical processing which extracts more than fifty per cent of lignin and could be used to produce Kraft pulp fibres (Tonoli et al. 2010). Savastano showed that the setting time of the cement matrix would be reduced while acid compounds are released from natural fibres. They also illustrated that lignin, sugar components and hemicellulose cause a disruption in the hydration of cement (Savastano Jr. et al. 2009).

Many research projects have concentrated on improving bonding at fibre-cement interfacial and increasing the durability of Kraft fibres in alkaline cement media (Ahmed and Mihashi 2007, Claramunt et al. 2011, Pacheco-Torgal and Jalali 2011, Savastano, Warden and Coutts 2003, Tolêdo Filho et al. 2003).

Sodium hypochlorite (at 7\% concentration) has been applied to fibres treated from waste paper and cardboard. The fibre content varied from $2-16 \%$ (by the weight of the cement) and the results showed that the effect of fibre treatment for the specimens reinforced by $16 \%$ fibre content were considerably improved (Bentchikou et al. 2012).

Ashori used calcium chloride (Cacl2) to treat Recycled Newsprint Paper (RNP). Their results showed that the specimens reinforced by $10 \%$ fibre content treated in 5\% concentration Cacl 2 could increase flexural strength of the cement boards (Ashori, Tabarsa and Valizadeh 2011).

Pehannich used different treatment using chemical aqueous solution of potassium silicate, sodium silicate and Silane on newspaper and unbleached Kraft fibres. They concluded that the mechanical properties of the specimens reinforced by treated fibres were greater than those specimens reinforced by untreated wood fibres (Pehanich, Blankenhorn and Silsbee 2004).

\section{MATERIALS, MIX DESIGN AND TEST}

The materials used to make the laboratory cement board specimens include; Portland cement CEM I (satisfied requirement of BS EN 197-1: 2000), potable water, Kraft pulp extracted from waste cardboard and refined by a laboratory refined machine. Three types of solutions (with a concentration of $5 \%$ and $10 \%$ ) used for the treatment of the fibres; Potassium Sulphate, Magnesium Sulphate and Sodium Silicate. For the treatment of Kraft fibres, the fibres were put in an appropriate solution for an hour then were washed using potable water.

In this research six groups of specimens were made as shown in table-1. In each group, there were six specimens. Specimens were subjected to flexural strength test, the first three after 7 days and the remaining three after 28 days.

Table 1. Mix design for making laboratory specimens

\begin{tabular}{|c|c|c|c|c|}
\hline Mix & Mix Code & $\begin{array}{c}\text { Cement } \\
\text { (gr) }\end{array}$ & $\begin{array}{c}\text { Dry mass of } \\
\text { cellulose fibre } \\
(\mathbf{g r})\end{array}$ & Treatment solution \\
\hline 1 & K3-P5 & 100 & 3.0 & $5 \%$ potassium sulphate \\
\hline 2 & K3-P10 & 100 & 3.0 & $10 \%$ potassium sulphate \\
\hline 3 & K3-M5 & 100 & 3.0 & $5 \%$ Magnesium Sulphate \\
\hline 4 & K3-M10 & 100 & 3.0 & $10 \%$ Magnesium Sulphate \\
\hline 5 & K3-S5 & 100 & 3.0 & $5 \%$ Sodium Silicate \\
\hline 6 & K3-S10 & 100 & 3.0 & $10 \%$ Sodium Silicate \\
\hline
\end{tabular}


In order to clarify the symbol used in table 1, it should be noted that K: Kraft. For instance K3-S10 represents the specimen reinforced by $3 \%$ Kraft fibre (by the weight of the cement) and the fibres were treated by Sodium Silicate in concentration of $10 \%$.

Flexural test. All specimens were subjected to flexural strength test according to BS EN 12467: 2004. During loading, the load and mid-span deflection were recorded so that the flexural behaviour of the specimens could be monitored from zero to fracture load.

\section{RESULTS, ANALYSIS AND DISCUSSION}

As mentioned previously, fibre content, water cement ratio and the type of cement are identical for all specimens; the only difference is the solution used to treat each group of specimens.

The symbols used in the graphs and discussion is based on the fibre content, type of treatment and date of testing for example K3-P10-D28 represents 3\% Kraft pulp fibre, Potassium sulphate at 10\% concentration and the specimen was subjected to flexural strength 28 days after casting/curing.

\section{Flexural strength}

Figure -1 shows the flexural strength of each group at day 7 and 28.

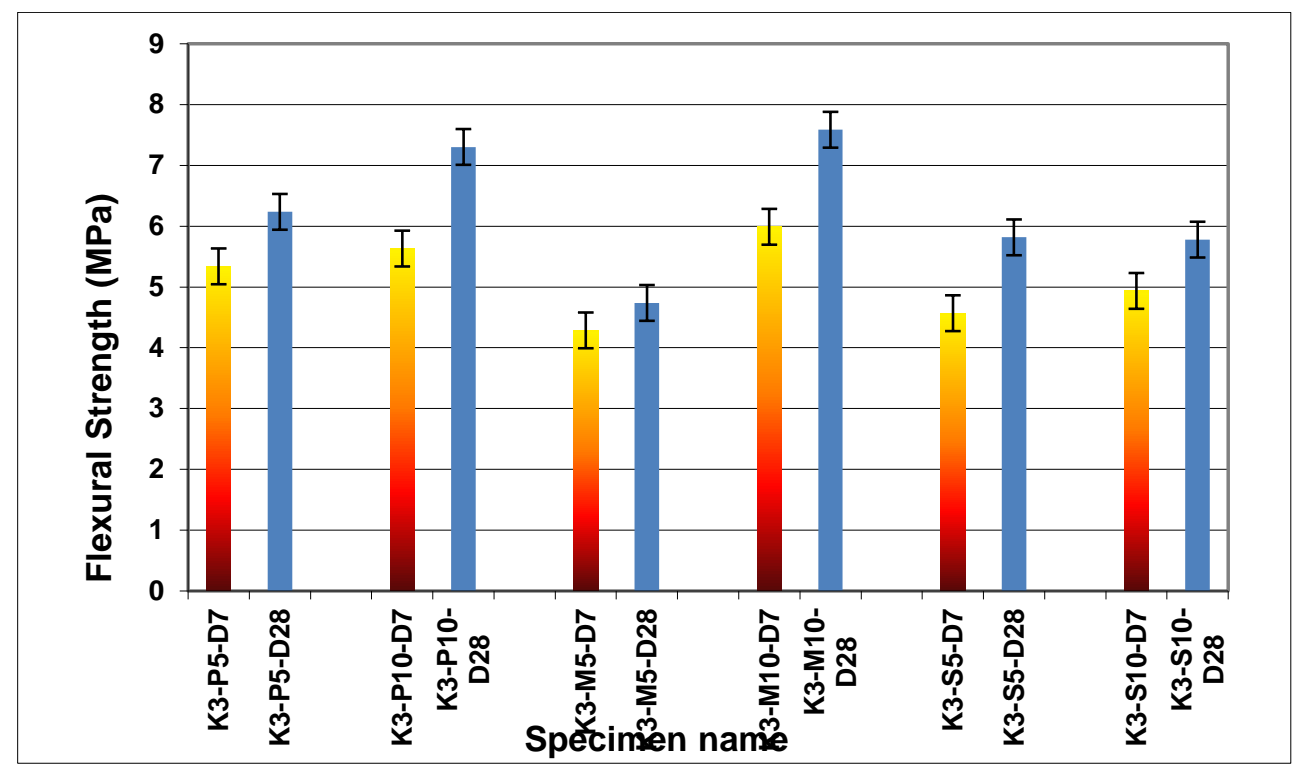

Figure 1. Flexural strength for all groups at day 7 and 28

The results shown in fig-1 clarify the following information:

- The flexural strength of all groups were higher at 28 days than at 7 days age.

- The highest flexural strength produced was from specimens reinforced by Kraft fibres treated by Magnesium Sulphate and Potassium Sulphate at 10\% concentration.

- Sodium Silicate did not improve flexural strength considerably in comparison to other groups.

Potassium sulphate. The results of flexural performance for specimens reinforced by Kraft fibres treated by Potassium Sulphate with 5\% and $10 \%$ concentration at the age of 28 -days have been illustrated in figure-2. As seen the maximum flexural strength of K3-P5-D28 and K3-P10_D28 is $6.2 \mathrm{MPa}$ and 7.3MPa, respectively. This shows an $18 \%$ increase in flexural strength. The areas under the curves are associated with toughness of the specimens for both samples and are almost identical; however the 
fracture of K3-P5-D28 seems to be more flexible rather than K3-P10-D28.

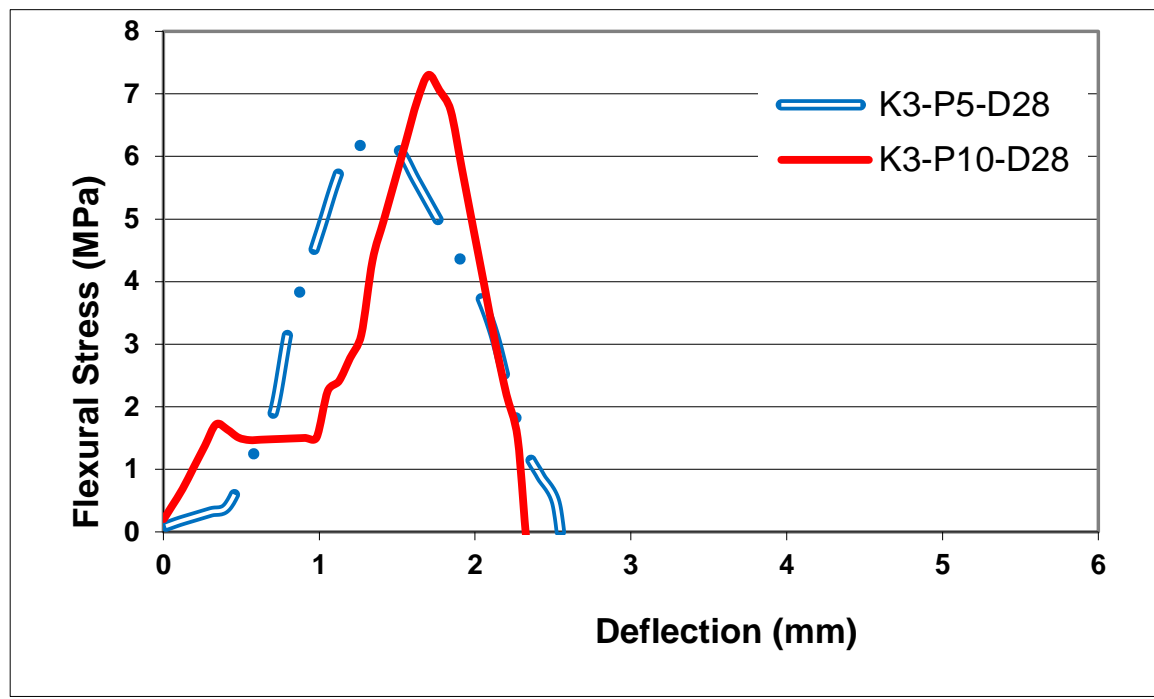

Figure 2. Flexural performance of specimens treated by Potassium Sulphate at concentration $5 \%$ and $10 \%$ at 28 -day

Magnesium Sulphate. Figure-3 compares 28-day flexural performance between the two groups of specimens that were treated by Magnesium sulphate at concentration of 5\% and 10\% (i.e. K3-M5-D28 and K3-M10-D28). As seen, Magnesium sulphate at 5\% concentration could not improve the flexural performance, whilst $10 \%$ concentration could increase the flexural strength up to 7.4 MPa. This may represent weak improvement of the bonds in the interfacial zone within the fibres and hydrated cement showing the effect of removing lignin from fibres.

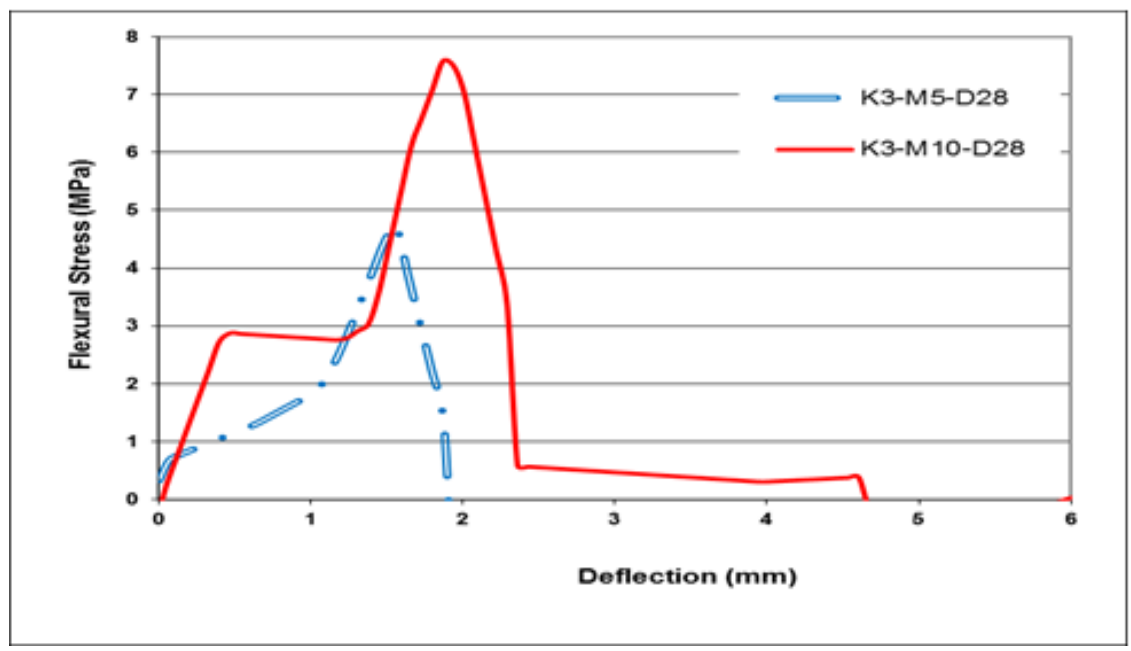

Figure 3. Flexural performance of specimens treated by Magnesium sulphate at concentration $5 \%$ and $10 \%$ at age of 28 -day

Sodium silicate. Figure- 4 shows the effect of Sodium Silicate at 5\% and 10\% concentration on treatment of Kraft pulp fibres used to produce fibre-cement board. As illustrated in figure-4, both $5 \%$ and $10 \%$ concentration have almost the same effect. 
In both group the highest flexural strength is about $6 \mathrm{MPa}$ and fracture toughness is almost identical. The most important results deduced from this behaviour could be considered as two hypotheses;

a) Sodium Silicate does not have an important effect on the treatment of Kraft fibres because as the concentration of solution increased there were no changes in flexural strength.

b) If Sodium Silicate is used at $5 \%$ concentration, it could remove all lignin from the fibres and as the concentration is increased, there is no lignin remaining on the fibres, hence, increasing from $5 \%$ to $10 \%$ concentration may not have any important effect on bonding within fibre-cement interfacial zone.

As the results of other groups (i.e. K3-P10-D28 and K3-M10-D28) showed greater flexural strength the hypothesis " $b$ " could not be acceptable and it seems hypothesis "a" is more realistic.

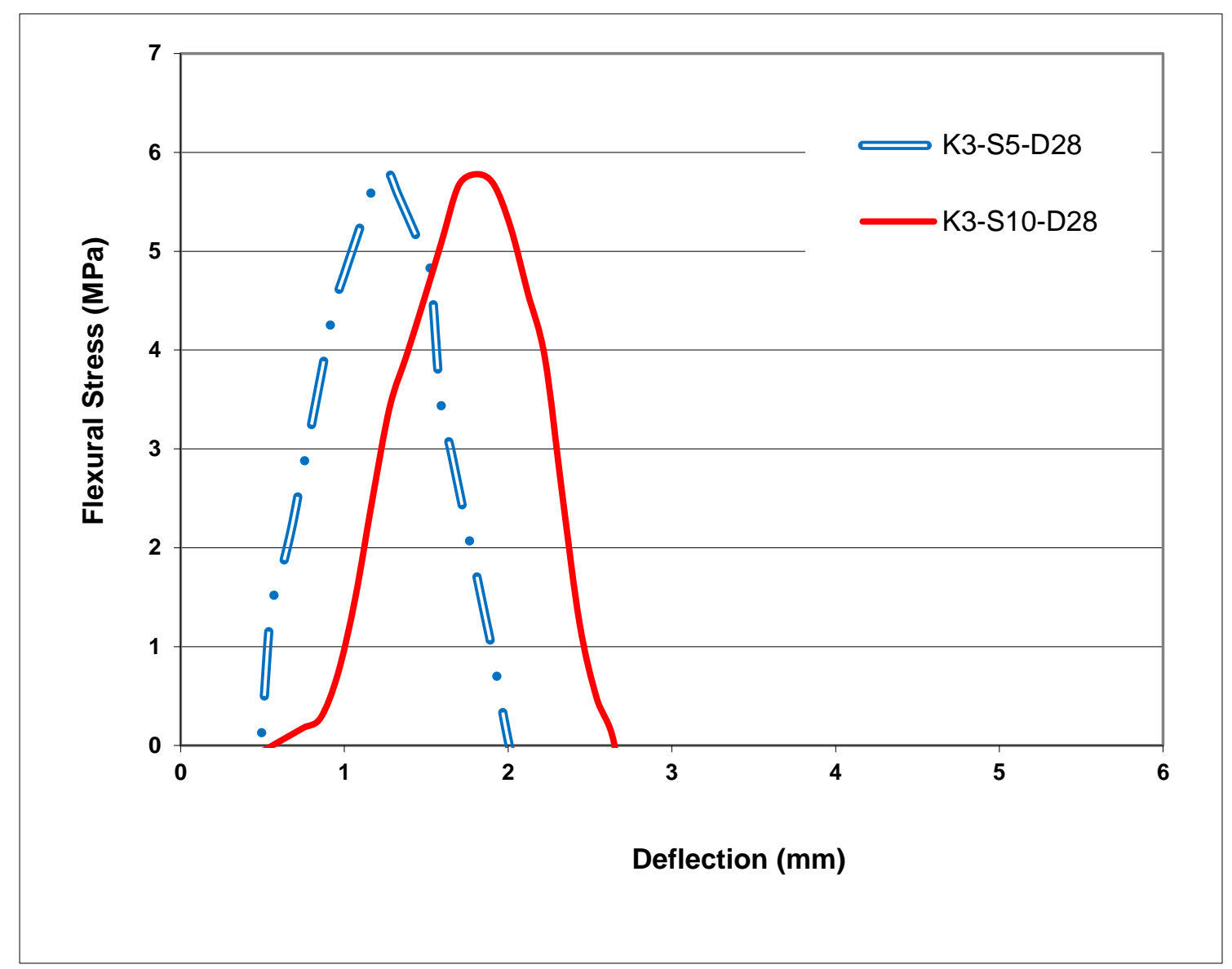

\section{Figure 4. Flexural performance of specimens treated by Sodium Silicate at concentration $5 \%$ and $10 \%$ at age of 28 -day}

Discussion. Figure 5 compares the flexural performance of all groups at 28 days. As can be inferred, flexural performance of the specimens reinforced by treated Kraft fibres by Magnesium Sulphate and Potassium Sulphate are very similar with each other in toughness and maximum flexural strength. The horizontal part of K3-P10-D28 and K3-M10-D28 may relate to the specimen settling on the jaws of the machine during the early stages of loading. Despite the two aforementioned sample, K3-S10-D28 could not improve the flexural behaviour of the cement board. 


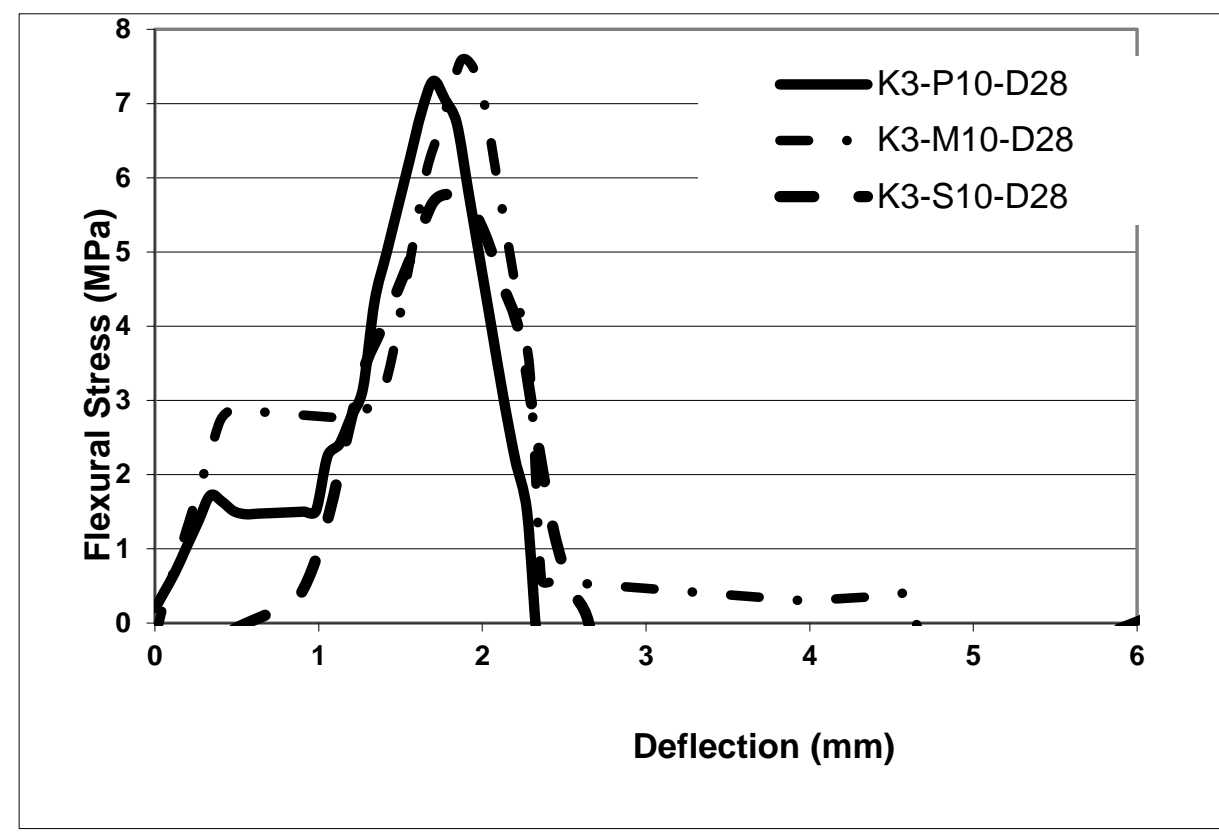

\section{Figure 5. Comparison of the flexural performance of the specimens at 28-day treated by different types of solution at $10 \%$ concentration}

From the results it can be seen that fibre treatment has two main effects: firstly, it reduces the amount of existing lignin in the fibres and secondly, it coats the fibres so that the alkaline materials produced by hydration cannot enter the fibre and cause damage to the lateral surface of the fibre.

\section{SUMMARY AND CONCLUSION}

In this research, the effect of three different types of treatment solutions on the flexural performance of cement board has been investigated. Those treatment solutions were Potassium Sulphate, Magnesium Sulphate and Sodium Silicate at 5\% and 10\% concentration. The results showed that Potassium Sulphate and Magnesium Sulphate at $10 \%$ concentration improved bonding within the fibre-cement interfacial zone which consequently led to an increase in flexural strength of the specimens up to $7.6 \mathrm{MPa}$ and $7.3 \mathrm{MPa}$, respectively.

Other results of this research are as follows;

- For all groups, the flexural strength of the specimens at 28-days was more than 7-day specimens. This shows that all applied treatment solutions could reduce deterioration of fibres in alkaline media produced from hydrated cement.

- The rate of increase in flexural strength from 7-day to 28-day for various types and concentration of treatment fibres varied between specimens. The highest rate of increasing flexural strength belongs to specimens treated by Potassium sulphate at $10 \%$ concentration

- Magnesium sulphate and Potassium Sulphate at $10 \%$ concentration had a similar effect on the fibres as the results of flexural performance show that the maximum bending strength and fracture toughness were almost identical.

- Sodium Silicate at $5 \%$ and $10 \%$ concentration could not improve the flexural performance of the specimens considerably and flexural strength of the specimens at both $5 \%$ and $10 \%$ concentration were recorded as being almost identical. 


\section{REFERENCES}

Ahmed, S. F. U. and Mihashi, H. (2007) 'A Review on Durability Properties of Strain Hardening Fibre Reinforced Cementitious Composites (SHFRCC)'. Cement and Concrete Composites 29 (5), 365-376

Ashori, A., Tabarsa, T., and Valizadeh, I. (2011) 'Fiber Reinforced Cement Boards made from Recycled Newsprint Paper'. Materials Science and Engineering: A 528 (25-26), 7801-7804

Bentchikou, M., Guidoum, A., Scrivener, K., Silhadi, K., and Hanini, S. (2012) 'Effect of Recycled Cellulose Fibres on the Properties of Lightweight Cement Composite Matrix'. Construction and Building Materials 34 (0), 451-456

Claramunt, J., Ardanuy, M., García-Hortal, J. A., and Filho, R. D. T. (2011) 'The Hornification of Vegetable Fibers to Improve the Durability of Cement Mortar Composites'. Cement and Concrete Composites 33 (5), 586-595

Coutts, R. S. P. (2005) 'A Review of Australian Research into Natural Fibre Cement Composites'. Cement and Concrete Composites 27 (5), 518-526

Ganjian, E. and Khorami, M. (eds.) (2008) The 11th International Inorganic Bonded Composite Conference. 'Application of Kraft and Acrylic Fibres to Replace Asbestos in Composite Cement Board'. held 5-7 Nov at Madrid, Spain

Jarabo, R., Monte, M. C., Blanco, A., Negro, C., and Tijero, J. (2012) 'Characterisation of Agricultural Residues used as a Source of Fibres for Fibre-Cement Production'. Industrial Crops and Products 36 (1), 14-21

Khorami, M. and Ganjian, E. (2011) 'Comparing Flexural Behaviour of Fibre-cement Composites Reinforced Bagasse: Wheat and Eucalyptus'. Construction and Building Materials 25 (9), 3661-3667

Pacheco-Torgal, F. and Jalali, S. (2011) 'Cementitious Building Materials Reinforced with Vegetable Fibres: A Review'. Construction and Building Materials 25 (2), 575-581

Pehanich, J. L., Blankenhorn, P. R., and Silsbee, M. R. (2004) 'Wood Fiber Surface Treatment Level Effects on Selected Mechanical Properties of Wood Fiber-Cement Composites'. Cement and Concrete Research 34 (1), 59-65

S.R., K. (2010) 'Cement-Bonded Composites from Lignocellulosic Wastes'. Construction and Building Materials 24 (8), 1323-1330

Savastano Jr., H., Santos, S. F., Radonjic, M., and Soboyejo, W. O. (2009) 'Fracture and Fatigue of Natural Fiber-Reinforced Cementitious Composites'. Cement and Concrete Composites 31 (4), 232243

Savastano, H., Warden, P. G., and Coutts, R. S. P. (2003) 'Potential of Alternative Fibre Cements as Building Materials for Developing Areas'. Cement and Concrete Composites 25 (6), 585-592

Tolêdo Filho, R. D., Ghavami, K., England, G. L., and Scrivener, K. (2003) 'Development of Vegetable Fibre-mortar Composites of Improved Durability'. Cement and Concrete Composites 25 (2), 185-196

Tonoli, G. H. D., Santos, S. F., Joaquim, A. P., and Savastano Jr., H. (2010) 'Effect of Accelerated Carbonation on Cementitious Roofing Tiles Reinforced with Lignocellulosic Fibre'. Construction and Building Materials 24 (2), 193-201 